\title{
Journal Proposal Template
}

This document outlines the types of questions that should be addressed during the initial stages of a new journal development. This conversation takes place between the journal hosting administrator or library publishing program and with the prospective journal manager. If both parties are in agreement on policies and processes moving forward, the information in this template will help make a successful journal. Templates like this are often used by library publishing programs, where the library acts as a 'digital publisher' for the journal and the journal manager and editorial staff are responsible for the management, review, editing, and submission process of the journal content.

Follow-up meetings may be needed after this initial conversation or answers to questions may later be supplied via email. Fields marked with an asterisk are required. Form is fill-able.

\section{Initial Journal Evaluation}

SECTION 1: BASIC JOURNAL INFORMATION

\section{Date of Meeting*}

Journal Manager* (Name and Affiliation)

\section{Journal Manager Email*}

Managing Editor (if different from Journal Manager)

Journal Email and URL (if existing) 
University Staff Manager Overseeing the Journal (applicable when the Journal Manager is not a member of the university/organization hosting the journal)

Principle Sponsor* (such as a School or Department responsible for journal content)

Other Sponsor(s) or Supporting Organizations (if any)

\section{SECTION 2: JOURNAL DESCRIPTION}

Journal Title*

Journal Abbreviation I Acronym*

Short description* (introduction for journal homepage and indexing, max 500 words) 
Keywords* (for journal indexing in search engines and databases; up to 8 max)

\section{Proposed language(s) of the journal}

Does the Journal already exist in print?

No

Yes (see next line)

If Yes, provide the ISSN number for print:

Explain where print copies are available and the permanent location address of the print journal.

Does the Journal already exist online? $\quad \square$ No $\quad \square$ Yes (see next line)

If Yes, provide the EISSN number for the online version:

Provide the URL of the online journal:

Proposed File Formats of Published Journal* (select all that apply)

$\square$ PDF $\quad \square$ HTML $\quad \square$ EPUB $\quad \square$ OTHER

Does your editorial team have the technical skills needed to create all of these selected file formats?

No (see next line)

Yes

If No, please explain which formats will be created in-house and which (if any) you may need assistance with: 


\section{Proposed Journal Distribution*}

By default, new journals will be available online. Do you also plan to distribute in print?

$\square$ No $\quad \square$ Yes (if Yes, describe printing process below)

Journal Contact Address* (to be placed on website)

Journal Contact Email* (to be placed on website)

Journal Technical Support Contact (name and email to be placed on website)

\section{SECTION 3: ABOUT AND POLICIES}

Focus and Scope* (typical scope length is $300-600$ words)

When drafting a scope, consider: What is the journal about? What do you hope to achieve as a journal? Is there a strong disciplinary base or purpose for this journal?

$\square$ Check here if journal manager will email the Scope later

$\square$ Check here when received and record date:

$\square$ Or write the scope below: 
Journal History (typical history length is 50-200 words)

When drafting the "About" Journal section for the website, consider what potential readers and authors may want to know about how the journal was established and progressed.

$\square$ Check here if journal manager will email the Journal History later

$\square$ Check here when received and record date:

$\square$ Or write the journal history below: 


\section{Editorial Staff and Peer Reviewers*}

Will the Journal have an editorial board, reviewers, or designated copy-editing or layout editing staff? If so, are these participants already secured? Please explain.

\section{Review Policy* (length varies)}

When drafting a review policy, consider describing the criteria, principles, required citation formats, supplementary file types authors may submit, misconduct issues (such as plagiarism, falsified data/citations), time taken for decisions, and feedback, etc. (beneficial for readers and authors)

$\square$ Check here if journal manager will email the Review Policy later

$\square$ Check here when received and record date:

$\square$ Or write the review policy below: 
Open Access Policy* (length and content varies)

When drafting an open access (OA) policy, consider whether your online journal will be completely open access (without article processing charges)? Will open access be delayed for some content? Will the journal have a set reuse policy for all articles, such as all articles using the same Creative Commons (CC) license? Or will individual authors select their own CC license?

An example of a simple OA policy reads:

This journal provides immediate open access to its content on the principle that making research freely available to the public supports a greater global exchange of knowledge. There are no article submission or processing charges. Authors retain copyright and grant the journal right of first publication with the work simultaneously licensed under a Creative Commons AttributionNonCommercial-ShareAlike 4.0 International License that allows others to share the work with an acknowledgment of the work's authorship and initial publication in this journal.

$\square$ Check here if journal manager will email the Open Access Policy later

$\square$ Check here when received and record date:

$\square$ Or write the open policy below: 
Creative Commons (CC) License* (indicates whether a journal will allow reuse and remixing of content in accordance with a CC License)

For more information on what each CC license entails, visit

http://creativecommons.org/licenses

Do you plan to use a CC License?

$\square$ No $\quad \square$ Yes

If No, please explain why:

If Yes, please select which CC License:

$\square$ CC-BY

$\square$ CC BY-NC $\square$ CC-BY-SA

$\square$ CC BY-NC-SA $\square$ CC-BY-ND

$\square$ CC BY-NC-ND 
Copyright Policy* (length and content varies)

When drafting a copyright policy, consider whether the journal will allow authors to retain copyright and grant you (the journal) a license to publish? Or will you require authors to transfer copyright to the publisher? [You will need a short statement for the journal website and a full author Agreement].

$\square$ Check here if journal manager will email the Author Agreement later

$\square$ Check here when the Author Agreement is received and date:

$\square$ Check here if journal manager will email the Copyright Policy later

$\square$ Check here when received and record date:

$\square$ Or write the copyright policy below: 
Third Party Copyright Policy* (length and content varies)

When drafting a third party copyright policy, consider whether the journal will require authors to clear third party copyright for online use. Will the journal's submissions contain images, figures, or sound that the authors did not create themselves? Are there additional legal issues to consider?

If necessary, contact the University Counsel or legal office of your organization for advice.

$\square$ Check here if journal manager will email Third Party Copyright Policy later

$\square$ Check here when received and record date:

$\square$ Or write the copyright policy below: 
Competing Interests Statement (length and content varies)

When drafting journal policies, consider whether the journal will require a Competing Interests Statement in the Author Guidelines. This can describe any policy for handling potential conflicts of interest from editors, authors, or reviewers.

Does the journal require a Competing Interests Statement?

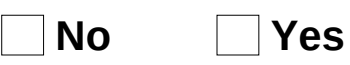

$\square$ Check here if the Competing Interests Statement will be sent later

$\square$ Check here when received and record date:

$\square$ Or write the statement below:

Other Policies (length and content varies)

Example policies you may want to consider include policies related to privacy, diversity, or code of ethics. Describe any other policies of interest below.

\section{SECTION 4: INDEXING, PROCESSES, AND FUNCTIONALITY}

\section{Digital Object Identifiers (DOI)*}

A DOI uniquely identifies an article (similar to how an Orchid ID uniquely identifies an author). Using a DOI is helpful but not required. There is a cost associated with the registration of each article (currently about $\$ 1 \mathrm{US}$ ), which may or may not be an option for the library publishing program. If not, journal managers who wish to use DOIs 
(without assistance from the library publishing program) can register on their own. If interested in using DOIs, the following agencies offer this service: CrossRef, DataCite, and others as seen at https://www.doi.org/registration_agencies.html.

Does the library publishing program currently offer this service? $\quad \square$ No $\quad \square$ Yes

Does the Journal want to use DOIs?

If Yes, who will pay the associated fees?

Does the Journal need a new ISSN?*

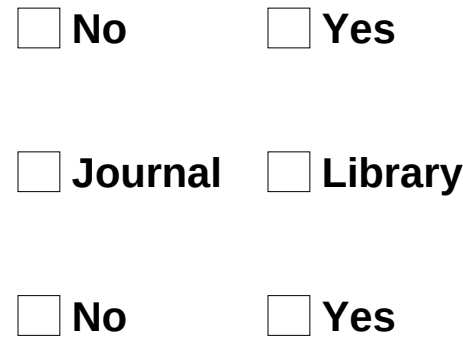

If Yes, each version of the journal (online and print) needs its own ISSN. Do you need an ISSN for print only, EISSN for online only, or both an ISSN and EISSN?

For a description of the International Standard Serial Number (ISSN), visit http://www.issn.org/understanding-the-issn/what-is-an-issn/

\section{Long-Term Preservation (optional)}

Does the library publishing program currently offer long-term preservation through a standardized process? (such as LOCKSS, CLOCKKS, etc).

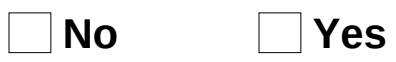

If Yes, does the Journal want to participate in this long-term preservation option?

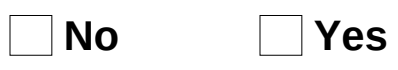




\section{Review Process Management*}

The library publishing program may offer various software to host the journal. Please select the option available to journal managers:

$\begin{array}{ll}\square \text { Dspace } \square \text { Digital Commons } & \square \text { Open Journals Systems (OJS) } \\ \square \text { Eprints } \quad \square \text { Scholastica } & \square \text { Non-repository website such as } \\ \text { Drupal, Wordpress, Other }\end{array}$

Clairfy (if needed):

Does the Journal plan to use the repository software selected above to manage the review process? Or does the Journal only want to publish the final journal issue to the site?

$\square$ Use repository for management, review processes, and publishing $\square$ Use repository only for publishing

Comments (if any)

\section{Scheduling Frequency*}

Please describe how often the journal will publish a new issue (include how many volumes and issues each year and estimated month(s) of publication if known): 


\section{Journal Sections*}

Please describe what sections will be in the journal (such as Articles, Reviews, Proceedings, Essays, Case Studies, Student Work, etc). Will there be a full issue option or only individual articles?

\section{Review Process*}

Please describe the review process for each type of section/content. This can include whether a specific section is peer-reviewed, editor-reviewed, or not. Which sections use blind reviews (single, double, open)?

\section{Author Submission File Formats* (select all that apply)}

What file formats will the Journal accept for article submission? (this is different from the file format of the final publication).

$\square$ DOC $\quad \square$ DOCX $\quad \square$ CSV $\quad \square$ ODF $\quad \square$ PDF $\quad \square$ XML


If you need authors to be able to submit additional file formats, please specify:

\section{Production Tools*}

Please describe the production tools (software) you will use to review manuscripts and produce the final publishable format (for example, Word, Adobe Acrobat, Adobe In Design, some other image software or layout software, etc)

\section{Additional Information}

If there is any other information that would be helpful for the Journal's About page, please provide it below: 


\section{SECTION 5: CUSTOMIZATION}

Typical library publishing programs provide basic customization. For detailed or advanced customization, it is best to design a separate form or template to use as a guide. The following section only represents basic customization content.

\section{Journal Website Homepage*}

Does the Journal have a logo?

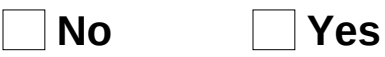

Does the Journal want the logo on the journal website?

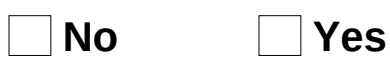

If Yes, send two copies of the logo (sizes $300 \times 300$ and $150 \times 150$ thumbnail) to the library contact via email. Keep in mind, logo design best practice is keeping it simple, the best logos are not complicated).

By default, the website footer will read:

Journal Hosting Supported by Name of Library Publishing Program, Name of University or Organization ISSN: xxxx-xxxx

What information does the Journal want in the website's footer if different from above default example?

\section{Existing Content*}

Does the Journal have existing content to be uploaded to the site? If so, please describe, including the date of first publication, if any author fees were charged, and the reason for changing publishers: 
Does the existing content have proper permissions for being uploaded to the new journal website?*

For publishing agreements between the authors and the journal that were used in previous issues: do these agreements also apply to the journal's new website?. Please describe any concerns regarding the transfer of previous issues to the new website, including who owns the copyright for back issues. Include number of back issues.

Does the existing content have any other contractual agreements with other publishers or indexing services? If so, please explain.

Does the Journal want content to be archived in the library's institutional repository (if applicable)? $\quad \square$ No $\quad \square$ Yes

\section{First Publication Goals*}

When do you expect the journal's new website to go live?

What is your target date for the first issue on the new site? Comments (if any) 


\section{SECTION 6: NEXT STEPS AND CHECKLIST}

Suggested next steps, check off as they are completed:

After the meeting, the library publishing program will create and send a list of the missing information from this template that the journal manager agreed to send later via email.

Date Completed

The journal manager will gather the required information and email it to the library contact.

Date Completed

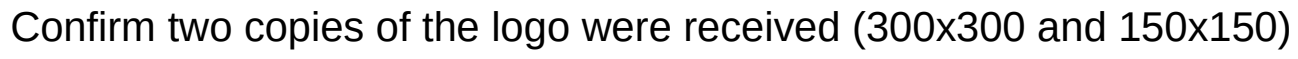
Date Completed

The library contact will check to see if the journal title is already in use.

Date Completed

The journal manager will identify other journals with similar content or scope and share with the library contact.

Date Completed

Together, the library contact and journal manager will determine how the journal can distinguish itself from these other journals and make adjustments.

Date Completed

Both the library publishing program and journal manager sign a formal agreement or Memorandum of Understanding (MOU) that states the expectation of both parties in regards to the new journal. This includes acknowledgment that the journal will be open access (free for authors to submit manuscripts and free for readers to access journal content)

The MOU is a separate document and process that should be completed once there has been an initial meeting and conversations surrounding the content in this Journal Proposal Template.

Date Completed

[ end ]

Created by A.Miller (2020). Journal Proposal Template. Adapted from material by the University of St Andrews Library and Boston College Libraries. This work is licensed under a Creative Commons Attribution-NonCommercial-ShareAlike 4.0 International License 